\title{
Immunization of children from parents' perspective
}

\author{
Jacek Majewski, Marcin Madziarski, Justyna Pająk, Maciej Majewski, Leszek Szenborn \\ $1^{\text {st }}$ Department and Clinic of Paediatric Infectious Diseases, Wroclaw Medical University, Wroclaw, Poland
}

\section{ABSTRACT}

Aim of the study: The aim of the study was to determine parents' sources of knowledge of vaccinations and their attitude to recommended vaccines, and to assess the effectiveness of educational intervention in terms of encouraging parents to vaccinate their children.

Material and methods: Two methods were used. The first was an original survey collected in health clinics from parents seeing their paediatrician (303 surveys). The second survey had two parts, and they were collected before and after a lecture on recommended vaccines ( 35 surveys). The answers in both parts were then compared. Several questions with answers on a Visual Analogue Scale were used.

Results: The source of knowledge of vaccination was a doctor/health service (262/303, 86\%), family or friends $(94 / 303,31 \%)$, the Internet $(86 / 303,28 \%)$, media $(49 / 303,16 \%)$, and others $(11 / 303,4 \%)$. In the majority of cases $(152 / 303,50 \%)$ the media message was interpreted as encouraging to vaccinate. A doctor/health service remains an ultimately decisive (257/303, 85\%) source of information on vaccinations. 55/303 (18\%) interviewees had personal experience of side effects of vaccination, and 10 of them erroneously pointed at autism as a side effect in their opinion. Acceptance and willingness for recommended vaccines was increased after the lecture.

Conclusions: Doctors and health service remain the most important and decisive source of knowledge of vaccinations. Being in favour of immunisation depends neither on education nor on place of residence. Parents' direct or indirect experience of vaccine injury is often misinterpreted (e.g. autism) but plays an important role in making decisions about recommended immunisation. The lecture proved its efficiency in educating parents about recommended vaccines and their benefits.

\section{KEY WORDS:}

vaccinations, lecture, children, survey.

\section{INTRODUCTION}

Immunisation is the most efficient method of infectious disease prevention and one of the most common prophylactic measures [1]. It is currently estimated that it contributes to the decrease in deaths worldwide by 2-3 million annually. In Poland its realisation is specified in the Immunisation Schedule, which consists of two parts: mandatory and recommended vaccinations. Although obtaining a patient's consent is necessary in the majority of medical activities of prophylactic or diagnostic and therapeutic character, in the case of immunisation, public health protection has become a very important or even more urgent question. Polish legal regulations are not precise as regards ordering parents of an unvaccinated child to appear in the vaccination centre or in terms

\section{ADDRESS FOR CORRESPONDENCE:}

Leszek Szenborn, 1st Department and Clinic of Paediatric Infectious Diseases, Wroclaw Medical University,

2-2a Chałubińskiego St., 50-368 Wroclaw, Poland, ORCID: 0000-0001-6574-8229,

e-mail: leszek.szenborn@umed.wroc.pl 
of imposing a fine on them. In one of its proceedings in this case the Superior Administrative Court decided there is no legal basis to issue such an order because the regulations are not accurate enough [2]. At the same time, immunisation opponents, who spread their ideas easily in the Internet era, are more and more active in the world, and in Poland $[3,4]$. On the one hand, it poses a threat to unvaccinated children themselves, and, on the other hand, the decrease in vaccination coverage of the population may damage group immunity and lead to epidemic spread of disease also among people who are not vaccinated owing to medical counterindications. Moreover, due to vaccinations parents seldom come across diseases against which they vaccinate their children. In ancient China when variolation (artificial infection with non-attenuated virus - consisting of rubbing dried scabs derived from people suffering from smallpox into nasal mucous membrane) was first used the mortality from smallpox amounted to $25 \%$. In such circumstances even the $2.5 \%$ rate of fatal complications after such a prophylactic treatment was then acceptable.

Conducting preventive activities, including vaccinations, lies with a general practitioner (GP). As part of health education, they are also responsible for providing information on mandatory and recommended vaccinations [5]. Parents also find out about immunisation from other sources: family, friends, media, magazines, or the already mentioned Internet. It seems vital to assess which sources are crucial for parents. While, theoretically, it should have no impact on submitting children to mandatory vaccinations, it may gain importance in the case of recommended immunisation.

\section{AIM OF THE STUDY}

The aim of the study was to determine current sources of knowledge and parents' approach to immunisation, as well as to assess the effectiveness of educational intervention (lecture) as a means of improving parents' attitude to recommended vaccinations.

\section{MATERIAL AND METHODS}

The study involved a total of 338 participants aged from 19 to 51 years, the vast majority of whom (99\%) had at least one child. The study employed two methods. The first one was a survey drawn up by the authors and used during parents' visits with children at Primary Health Care Clinics in Dolnośląskie Voivodeship; Dzierżoniowski Poviat and in Wrocław in February 2017. Doctors handed the surveys to parents during appointments.

The survey consisted of three parts:

1) general part including sociodemographic questions (seven questions),

2) detailed part including questions about the sources of knowledge of vaccinations, parents' approach to rec- ommended vaccinations, personal experience of complications after immunisation, and contact with immunisation opponents and their opinion about them (13 questions),

3) additional part consisting of questions about influenza vaccination (two questions).

A total of 238 surveys were collected in two Primary Heath Care Clinics in Dzierżoniowski Poviat, and a further 65 surveys were gathered in one Primary Health Care Centre in Wrocław, which amounted to 303 surveys.

The answers to the questions concerning recommended vaccinations were used for detailed statistical analysis. The parents was asked if they would vaccinate their child against seasonal influenza, chickenpox, or meningococci with a recommended vaccine if they were free of charge (possible answers for each vaccine: "yes", "no", and "no opinion"). Next, the surveyed were divided into two groups:

1) "supportive" one, in which the parent did not mark the answer "no" for any vaccine and chose "yes" at least once;

2) "indecisive" one, in which they ticked "no" for at least one vaccine.

The first group amounted to 160 people, while there were 99 people in the second one. In order to compare the two groups in terms of different nominal variables the (Pearson's) $\chi^{2}$ test of independence was applied.

The core of the second part of the study was educational intervention and a double anonymous series of questions before and after a lecture clarifying parents' concerns and presenting arguments for recommended vaccination (chargeable). The study was conducted alongside a lecture organised by the "Akademia Malucha" ("The Little One Academy") educational company on the basis on voluntary, free, and unstimulated parents' participation, while the attendants' benefits derived from the lecture were purely educational. Thirty-five pairs of complete surveys were collected, in which, among other things, questions with responses marked on the Visual Analogue Scale (VAS) were applied. The range of the answer length was $16 \mathrm{~cm}$, and it was measured with the accuracy of up to $0.1 \mathrm{~cm}$.

The information from the surveys was gathered and analysed with, among other things, STATISTICA 12.5 program. The significance level for statistical tests was assumed at $p \leq 0.05$.

\section{RESULTS}

\section{SURVEYING PARENTS DURING THEIR VISIT AT CHILDREN'S CLINICS (PRIMARY HEALTH CARE)}

The survey return rate was $95.2 \%$ (238 out of 250 distributed surveys). Women constituted the majority of respondents ( $n=252,83 \%$ vs. 44 men, $17 \%$ ). Education varied, with an advantage of secondary education 
( $n=152,50 \%)$ over higher $(n=114,38 \%)$ and elementary education $(n=25,8 \%)$. A city or town was a more common place of residence $(n=255,84 \%)$ than the countryside ( $n=40,13 \%)$. The respondents usually had two children $(n=143,47 \%)$ or one child $(n=108,36 \%)$, and more rarely three or more $(n=43,14 \%)$. The vast majority declared vaccinating their children according to the Immunisation Schedule ( $n=285,94 \%)$, in a small number of cases children were not vaccinated due to a doctor's decision $(n=5,2 \%)$ or as a result of a parent's decision $(n=6,2 \%)$. The number of questions unanswered by the respondents in this part did not exceed $6 \%$.

In 152 cases (50\%) the surveyed evaluated the information on immunisation conveyed by the media as encouraging to vaccinate, in 45 cases as warning against vaccination (15\%), and difficult to assess in 86 cases (28\%). Twenty respondents (7\%) did not come across such information in the media. The surveyed indicated the following sources of knowledge of immunisation: doctor/health service (pointed out 262 times, 86\%), family/friends (94 times, 31\%), the media (49 times, 16\%), Internet/Internet forums (86 times, $28 \%$ ), and others (11 times, 4\%) - it was a multiple-choice question. However, when asked about the ultimately decisive source of information on vaccinations (a question to which only one answer could be chosen) the respondents indicated doctor/healthcare in 257 cases (85\%), family/friends in 12 cases (4\%), the media in one case $(<1 \%)$, Internet/Internet forums in four cases (1\%), and others in 12 cases (4\%). In 17 cases no answer was marked. In the "others" category five respondents stated that their own view/opinion was crucial.

The information provided by a doctor/health service was evaluated as sufficient in 244 cases (81\%) and insufficient in the remaining 59 cases (19\%). It was possible to indicate several sources simultaneously in the answer to the question. In 147 cases (49\%) the parent did not look for additional information on immunisation other than the one obtained from a doctor, while in the remaining cases they actively pursued such information by talking to their families/friends (113 responses, 37\%), looking for the information on the Internet/Internet forums (57 responses, $19 \%)$, or otherwise (14 responses, $5 \%)$.

Fifty-five respondents (18\%) were directly affected by vaccine injury (with complications), which occurred among their children or their families/friends. In the answer to the open question about the description of these complications, apart from such notions as fever, weakness, etc., they mentioned autism quite often (10 times, 18\%).

Parents were asked if they had heard about anti-immunisation movements. 137 respondents confirmed it (45\%), but only in four cases (3\%) did the surveyed agree with their message. The majority strongly disagreed with the message ( 53 cases, $39 \%$ ), somewhat disagreed ( 52 cases, $38 \%$ ), or had no opinion about it (27 cases, $20 \%$ ).

It was correlated which of the two groups the respondents belonged to ("supportive of vaccinations" 160 people and "indecisive" 99 people), what sociodemographic features they had, and what answers they gave to the rest of the questions. No relation between education or place of residence and belonging to one of the groups was indicated; however, active information pursuance had an adverse impact on the respondents' approach to recommended immunisation. The respondents from the "indecisive" group (33\% compared with $12 \%$ in the "supportive" one) considered the information communicated by a doctor/health service to be insufficient much more frequently. Also, the postvaccinal complications were more often recorded in the "indecisive" group (26\% compared with 13\% in the "supportive" group). Moreover, statistically significant differences regarding the source of knowledge of vaccinations were also indicated in the two groups - for the information derived from a doctor/ health service and from the Internet/Internet forums.

Another analysis involved the relation between being personally affected by the occurrence of vaccine injury (with complications) following children's immunisation and one's willingness to undergo regular vaccinations against seasonal influenza. Pearson's $\chi^{2}$ test of independence was applied. The results are presented in Table 1-3. It was indicated that a statistically significant difference

TABLE 1. Approach to free immunisation against influenza, meningococci, and chickenpox depending on education, place of residence, active pursue of information about vaccinations, and personal experience of vaccine injury

\begin{tabular}{|c|c|c|c|c|c|c|c|c|c|c|c|}
\hline \multirow[t]{2}{*}{ Group } & \multicolumn{3}{|c|}{ Education } & \multicolumn{2}{|c|}{ Place of residence } & \multicolumn{2}{|c|}{$\begin{array}{l}\text { Did they actively } \\
\text { pursue the } \\
\text { information about } \\
\text { vaccinations? }\end{array}$} & \multicolumn{2}{|c|}{$\begin{array}{l}\text { Did they consider the } \\
\text { information obtained } \\
\text { from a doctor/health } \\
\text { service to be sufficient? }\end{array}$} & \multicolumn{2}{|c|}{$\begin{array}{l}\text { Were they } \\
\text { directly } \\
\text { affected by } \\
\text { vaccine injury? }\end{array}$} \\
\hline & Elem. & Second & Higher & City & Country & No & Yes & Yes & No & Yes & No \\
\hline \multirow[t]{2}{*}{ Supportive } & 15 & 77 & 62 & 136 & 22 & 90 & 70 & 141 & 19 & 21 & 138 \\
\hline & $10 \%$ & $50 \%$ & $40 \%$ & $86 \%$ & $14 \%$ & $56 \%$ & $44 \%$ & $88 \%$ & $12 \%$ & $13 \%$ & $87 \%$ \\
\hline \multirow[t]{2}{*}{ Indecisive } & 5 & 45 & 45 & 80 & 16 & 38 & 61 & 66 & 32 & 26 & 73 \\
\hline & $5,3 \%$ & $47,3 \%$ & $47,3 \%$ & $83 \%$ & $17 \%$ & $38 \%$ & $62 \%$ & $67 \%$ & $33 \%$ & $26 \%$ & $74 \%$ \\
\hline $\begin{array}{l}\text { Difference } \\
\text { significance }\end{array}$ & \multicolumn{3}{|c|}{ NS } & \multicolumn{2}{|c|}{ NS } & \multicolumn{2}{|c|}{$p=0.005$} & \multicolumn{2}{|c|}{$p<0.001$} & \multicolumn{2}{|c|}{$p=0.008$} \\
\hline
\end{tabular}


TABLE 2. Approach to free immunisation against influenza, meningococci, and chickenpox depending on the source of knowledge of vaccinations indicated by the respondents

\begin{tabular}{|c|c|c|c|c|c|c|c|c|}
\hline \multirow[t]{3}{*}{ Group } & \multicolumn{8}{|c|}{ Indicated sources of knowledge of vaccinations } \\
\hline & \multicolumn{2}{|c|}{ Doctor/health service } & \multicolumn{2}{|c|}{ Family/friends } & \multicolumn{2}{|c|}{ Media } & \multicolumn{2}{|c|}{ Internet/Internet forums } \\
\hline & Yes & No & Yes & No & Yes & No & Yes & No \\
\hline \multirow[t]{2}{*}{ Supportive } & 147 & 13 & 43 & 117 & 24 & 136 & 35 & 125 \\
\hline & $92 \%$ & $8 \%$ & $27 \%$ & $73 \%$ & $15 \%$ & $85 \%$ & $22 \%$ & $78 \%$ \\
\hline \multirow[t]{2}{*}{ Indecisive } & 77 & 22 & 33 & 66 & 15 & 84 & 39 & 60 \\
\hline & $78 \%$ & $22 \%$ & $33 \%$ & $67 \%$ & $15 \%$ & $85 \%$ & $39 \%$ & $61 \%$ \\
\hline $\begin{array}{l}\text { Difference } \\
\text { significance }\end{array}$ & \multicolumn{2}{|c|}{$p=0.001$} & \multicolumn{2}{|c|}{ NS } & \multicolumn{2}{|c|}{ NS } & \multicolumn{2}{|c|}{$p=0.002$} \\
\hline
\end{tabular}

TABLE 3. Willingness to submit to free seasonal influenza vaccination depending on personal experience of vaccine injury in children

\begin{tabular}{|l|c|c|c|c|c|}
\hline \multirow{2}{*}{$\begin{array}{l}\text { Were you directly affected by } \\
\text { vaccine injury? }\end{array}$} & \multicolumn{5}{|c|}{$\begin{array}{c}\text { Would you get vaccinated regularly (once a year) against seasonal influenza if it was free } \\
\text { of charge? }\end{array}$} \\
\cline { 2 - 6 } & Definitely no & Rather no & No opinion & Rather yes & Definitely yes \\
\hline Yes & 15 & 15 & 7 & 11 & 5 \\
\cline { 2 - 6 } & $28 \%$ & $28 \%$ & $13 \%$ & $21 \%$ & $9 \%$ \\
\hline No & 23 & 73 & 32 & 79 & 31 \\
\cline { 2 - 6 } & $10 \%$ & $31 \%$ & $13 \%$ & $33 \%$ & $13 \%$ \\
\hline Difference significance & \multicolumn{7}{|l|}{$p=0.007$} \\
\hline
\end{tabular}

in willingness to submit oneself to influenza vaccinations depended on whether or not the respondent had personal experience of postvaccinal complications in children.

\section{EDUCATIONAL INTERVENTION}

The survey return rate was $100 \%$ (35 sets out of 35 distributed ones). Thirty-two women and three men aged from 24 to 41 years took part in the study. Thirtyfour respondents claimed to have higher education and one surveyed person had secondary education. Thirtythree out of 35 respondents were employed. A city/town was indicated as a place of residence 32 times, while the countryside three times. At the time of the survey four respondents declared to be childless, 25 respondents claimed to have one child, and six of the surveyed claimed to have two children.

The surveyed answered questions related to their approach to recommended immunisation for children, i.e. chickenpox, pneumococci (which was among the recommended vaccinations at the time of the survey) and meningococci type B and C. A question about the necessity to vaccinate was asked for each vaccine before and after the lecture. Then any change in the parents' approach was checked statistically. In connection with the distribution of answers (collected as continuous data due to VAS application), which did not meet the standards of normal distribution, Wilcoxon's signed-rank test was applied. Statistically significant changes indicating that the respondents understood the necessity and benefits resulting from the application of recommended vaccinations were observed for pneumococci $(p=0.011, n=19)$ and meningococci type $\mathrm{B}$ and $\mathrm{C}$ vaccinations $(p=0.007$, $n=24)$. In the case of chickenpox vaccination, the improvement of the parents' approach was borderline statistically significant $(p=0.053, n=15)$.

The survey consisted of four questions (two before and two after the lecture) with VAS answers divided into subpoints for a particular vaccine (chickenpox, pneumococci, meningococci B and C). Then the variation of answers to different subpoints of the same question was analysed. Importantly, the variation was examined in each respondent for a particular question. The coefficient of variation (the ratio of the standard variation to the mean), which is a measure of dispersion of a given factor - in this case the answer depending on the type of vaccination, was applied. As a result, it was possible to assess whether an average respondent gave similar answers to various subpoints of a question (concerning chickenpox, pneumococci, and meningococci type B and C, respectively), and then the coefficient of variation was potentially high or treated perfunctorily, and their responses to subsequent subpoints were similar (the coefficient of variation of the answer was low). The data were collected and presented in a box and whisker plot (Fig. 1). For the answers obtained before the lecture (questions 1 and 2) the range 
of middle $25-75 \%$ cases of the coefficient of variation was below $50 \%$, while for the responses given after the lecture (questions 3 and 4 ) the coefficient of variation did not exceed $20 \%$, with the mean below $10 \%$.

The survey also included such questions as: how a respondent evaluates their knowledge of recommended vaccinations following the educational intervention (question 5) and if they find the information conveyed in the lecture useful (question 6). The responses were collected in the VAS scale and presented graphically (Fig. 2). Both knowledge after the lecture (mean $11.7 \mathrm{~cm}$, median $11.3 \mathrm{~cm}$ ) and the usefulness of the presented content (mean $13.5 \mathrm{~cm}$, median $15 \mathrm{~cm}$ ) were evaluated highly by the respondents; however, the question of the usefulness information received single low marks, which increased the spread of results.

A considerable improvement in the respondents' knowledge was also confirmed by a change in the answer to the question of whether a healthy, normally developing child can develop, respectively: meningococcal septicaemia, pneumococcal meningitis, or varicella encephalitis. It was possible to choose one of the following answers: "yes", "not enough knowledge of this topic", or "no". Nobody marked the answer "no". Cochran's Q test was applied for statistical analysis (two dichotomous variables - "yes" and "not enough knowledge of this topic"). The results are presented on a graph (Fig. 3). In each case there was a statistically significant improvement of parents' knowledge, which was visible in the decrease in the "not enough knowledge of this topic" answer from over $50 \%$ to less than $10 \%$ after the lecture.

\section{SUMMARY OF THE RESULTS}

- In the majority of cases (50\%) the media message was interpreted as encouraging to vaccinate.

- A doctor/health service is the most common (86\%) and ultimately decisive ( $85 \%$ ) source of information on vaccinations.

- $18 \%$ respondents claimed to have personal experience of vaccine injury, and one in five included autism in this category.

- Dependence was proven between active pursuance of information about vaccinations, considering the information obtained from a doctor to be sufficient, personal experience of postvaccinal complications, indicated sources of knowledge of immunisation, and the attitude to recommended vaccinations.

- Effective change of parents' approach to recommended vaccinations and the awareness of the risk of developing illnesses without getting vaccinated was seen after educational intervention.

- A low variation of response of the average respondent in questions with several subpoints concerning different pathogens (especially after the educational intervention) was noted.

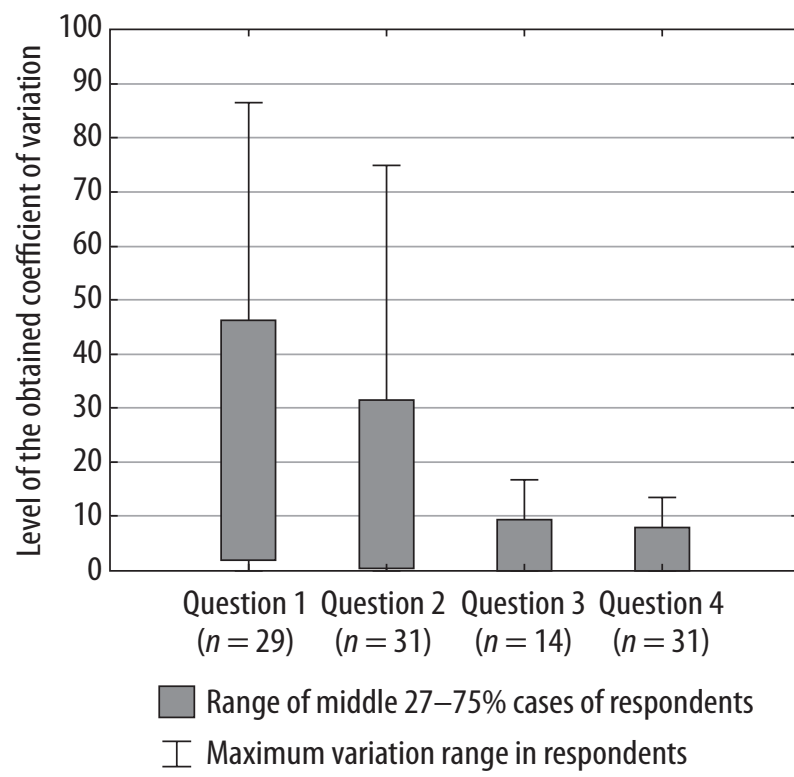

FIGURE 1. Coefficient of variation of the answers to identical questions concerning various vaccinations (a survey connected with educational intervention; questions 1 and 2 asked before the intervention, questions 3 and 4 following the intervention)

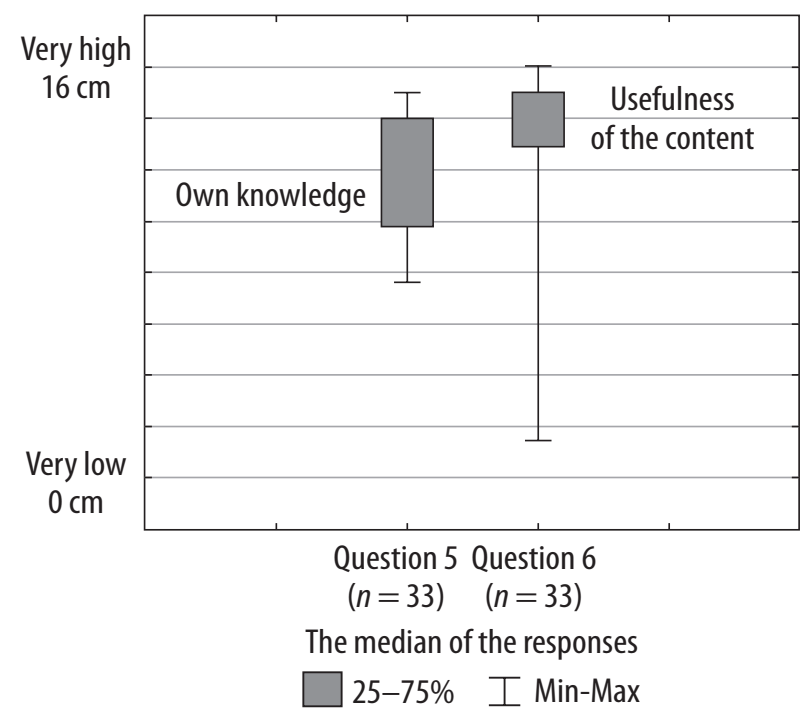

FIGURE 2. Respondents' assessment of their knowledge following the educational intervention and the usefulness of the conveyed information expressed in VAS (lowest: $0 \mathrm{~cm}$, highest: $16 \mathrm{~cm}$ )

\section{DISCUSSION}

Currently, parents are less and less frequently affected by infectious diseases against which children are vaccinated and, consequently, pay more attention to the occurrence of vaccine injury. As a result, they are more inclined to make a decision according to the "forgotten benefits and overstated risk" principle, which may increase their doubts about performing immunisation [6] - especially if they derive such information from unreliable non-medical sources. 
Can a previously healthy, normally developing child develop:

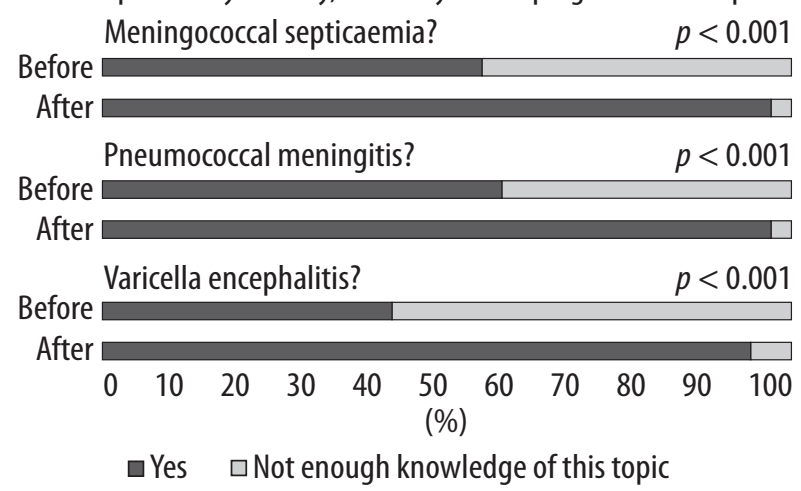

FIGURE 3. Change in parents' knowledge of the possibility of the occurrence of certain chickenpox complications and invasive infections caused by pneumo- and meningococci in a healthy child. The comparison of answers before and after the lecture

The conducted research confirmed that a doctor and health service have ceased to be the only source of information about vaccinations, which is confirmed in the literature [7]. Talks with one's family or friends, as well as the Internet and visited Internet forums have also gained importance. The performed analysis has proven a connection between drawing information from the Internet and a more reluctant approach to recommended immunisation for children. The reason for this phenomenon is searching for arguments to justify a sceptical approach. Similar trends were observed among the participants of an antenatal class, who looked for information on immunisation prior to the birth of their children. This active pursuance of information - often the symptom of concern about the child or willingness to gain broader knowledge - has an adverse impact on subsequent attitude to voluntary vaccinations, probably as a result of encountering overexposed, often fake information on postvaccinal complications on the Internet [8]. It looks otherwise if one only relies on a doctor/health service in this regard. The role of a doctor in resolving doubts or answering parents' questions is still crucial, which is reflected in other writers' publications [9].

One can find reports indicating a relation between better education and a more favourable approach to recommended vaccinations in relevant literature [8]. However, this research has not demonstrated such a connection - as in the case of place of residence. As observed in the research, personal experience of vaccine injury, which parents defined as "complications", appeared to be crucial. On the one hand, it was confirmed that such an experience has a negative impact on submitting one's own child to recommended vaccinations, and on the other hand, it was indicated that parents often misinterpreted the connection between certain diseases or clinical conditions with vaccinating children. A particularly conspicuous example is associating vaccinations with autism, which is frequently mentioned as an immunisation complica- tion. Conducted epidemiological research on the alleged relation between measles-mumps-rubella (MMS) vaccination and autism did not confirm any interdependence $[10,11]$. A direct cause of spreading this harmful opinion was removed from Lancet scientific magazine owing to its methodological unreliability and falsification of results, which was proven by scientific investigation. Nevertheless, the repercussions of Wakefield et al.'s publication resulted in the emergence of numerous outbreaks of measles and endemic appearance of infections in, among other places, Britain due to an increased number of unvaccinated children [12]. Explaining the lack of connection to anxious parents may result in their increased confidence in immunisation. Simultaneously, our research has proven that parents' personal experience of vaccine injury in their immediate environment has a negative influence on their approach to submitting themselves to seasonal influenza vaccination (assuming it was free of charge). Questions about this disease were included in the study because it was influenza season at that time.

\section{LECTURE ON IMMUNISATION AS EDUCATIONAL INTERVENTION}

The performed analysis proved the efficiency of this educational method. Due to the application of the VAS system the responses were fully relativised in relation to the respondent's feelings [13]. However, one should bear in mind that the analysed group almost entirely consisted of people with higher education - selecting appropriate content and level for a diversified audience may appear to be difficult. The surveyed differentiated their answers depending on the vaccine to a small extent. The obtained mean value of the coefficient of variation was below $50 \%$ in every question. In the case of questions asked after the lecture the values fell below $10 \%$, which means statistically insignificant differentiation [14]. The average respondent gave very similar answers to particular questions in the VAS scale, regardless of the type of vaccine. It may indicate that immunisation is understood as a general concept - without paying attention to differences between particular substances or the diseases against which they are administered. In consequence, a sharp loss of confidence in one vaccine (as in the case of MMR vaccine) can lead to a decline of confidence in all of them.

Educational intervention proved efficient in statistical tests because it considerably improved parents' attitude to pneumococci and meningococci type $\mathrm{B}$ and $\mathrm{C}$. The result at the verge of statistical significance for measles could have been connected with the small size of the group $(n=15)$ that answered the question prior to and following the lecture. Additionally, the participants marked their knowledge of recommended vaccinations after the lecture and the usefulness of the presented content relatively highly. Following the intervention, the vast majority of the surveyed realised that a previously healthy, normally 
developing child can develop such diseases as meningococcal septicaemia, pneumococcal meningitis, or varicella encephalitis.

An innovative approach to gathering responses marked on the VAS scale in the analysis of attitude to vaccinations and the influence of educational intervention were significant advantages of the study. A literature review did not indicate similar studies employing the VAS method for such a purpose. This step made it possible to show a "block" approach to the issue of immunisation with statistical methods, which would be impossible with the application of any other mode of responding. There is also a probability that the surveyed did not pay adequate attention to giving an appropriate response in the VAS scale, which may be confirmed by the fact that they frequently chose extreme values. Appropriate training of respondents and collecting surveys individually could eliminate this problem.

The small size of the examined group $(n=35)$ and the fact that some surveys were not completed correctly, which reduced the size of the group regarding particular questions even further, were the constraints in analysing the impact of educational intervention on the parents' approach. Moreover, the surveyed group mainly consisted of people with higher education ( $n=34$ out of 35 respondents), which is not representative for the general population.

\section{CONCLUSIONS}

1. A doctor constitutes the most important source of information for guardians who are about to take their final decision about vaccinations.

2. Being in favour of immunisation depends neither on education nor place of residence.

3. Guardians' direct or indirect experience of vaccine injury is often misinterpreted (e.g. autism) but plays an important role in making decisions about recommended immunisation, including seasonal influenza.

4. Lectures are an efficient educational intervention leading to improved acceptance of recommended vaccines among guardians.

5. Guardians generally consider immunisation to be one of the methods of preventing infections, without the distinction of particular hazards.

\section{DISCLOSURE}

The authors declare no conflict of interest.

\section{REFERENCES}

1. Raucci J, Whitehill J, Sandritter T. Chilhood immunizations (part one). J Pediatr Health Care 2004; 18: 95-101.

2. Augustynowicz A, Wrześniewska-Wal I. Aspekty prawne obowiązkowych szczepień ochronnych u dzieci. Pediatr Pol 2013; 88: 120-126.
3. Ołpiński M. Anti-Vaccination Movement and Parental Refusals of Immunization of Children in USA. Pediatr Pol 2012; 87: 381-385.

4. Szenborn L, Czajka H, Wysocki J. Kontrowersje wokół szczepień. Przegl Lek 2009; 66: 65-71.

5. Tymińska J, Wysocki J. Oszacowanie potrzeb edukacyjnych rodziców w zakresie szczepienia przeciwko pneumokokom na przykładzie wybranego gabinetu lekarza POZ. Nowa Pediatria 2015; 19: 101-107.

6. Gellin BG, Maibach EW, Marcuse EK. Do parents understand immunizations? A national telephone survey. Pediatrics 2000; 106: 1097-1102.

7. Lee B, Mueller L, Tilchin C. A systems approach to vaccine decision making. Vaccine 2017; 35 (Suppl 1): A36-A42.

8. Stahl J, Cohen R, Denis F, et al. General review: The impact of the web and social networks on vaccination. New challenges and opportunities offered to fight against vaccine hesitancy. Med Mal Infect 2016; 46: 117-122.

9. Yaqub O, Castle-Clarke S, Sevdalis N, et al. Review: Attitudes to vaccination: A critical review. Soc Sci Med 2014; 112: 1-11.

10. Taylor B, Miller E, Farrington CP, et al. Autism and measles, mumps, and rubella vaccine: no epidemiological evidence for a causal association. Lancet 1999; 353: 2026-2029.

11. Farrington CP, Miller E, Taylor B. MMR and autism: further evidence against a causal association. Vaccine 2001; 19: 3632-3635.

12. Atkinson P, Cullinan C, Jones J, et al. Large outbreak of measles in London; reversal of health inequalities. Arch Dis Child 2005; 90: 424-425.

13. Grundberg SM, Groshen S, Steinglass S, et al. Comparison of conditional quality of life terminology and visual analogue scale measurments. Qual Life Res 1996; 5: 65-72.

14. Zeliaś A. Metody statystyczne. Polskie Wydawnictwo Ekonomiczne, Warszawa 2000; 64. 